\title{
Educar para civilizar, civilizar para modernizar
}

\section{Educate to civilize, civilize to modernize}

DOI: https://doi.org/10.32870/dse.v0i21.709

\section{María Guadalupe García Alcaraz*}

Calderón Mólgora, Marco (2018). Educación rural, experimentos sociales y Estado en México: 1910-1933. México: El Colegio de Michoacán / Fideicomiso Felipe Teixidor y Monserrat Alfau de Teixidor.

Desde hace más de dos décadas, las investigaciones históricas han arrojado nueva luz sobre lo que la revolución y la posrevolución significaron para diferentes grupos sociales. Hoy sabemos, por ejemplo, que los cambios promovidos por intelectuales y políticos no fueron totalmente novedosos ni plenamente exitosos, y que los intentos del Estado por construir una nueva nación se entretejieron con las lógicas locales y regionales.

Entre 1910 y 1940 los procesos revolucionarios enmarcaron la formulación de proyectos mediante los cuales las elites buscaron impulsar cambios orientados a "sacar al país del atraso" y encaminarlo por la senda del desarrollo económico y de la homogeneidad cultural. Fueron tiempos de creación, invención y compromiso de numerosos agentes convencidos de la importancia de su participación para promover la mejora en el nivel de vida de la población. Sin embargo, en la historiografía contemporánea, no se trata de mostrar una versión en blanco y negro, sino de observar los matices. De ahí que hoy se reconozca que el camino para la definición y ejecución de trasformaciones sociales en ese periodo estuvo lleno discusiones, escollos y confrontaciones. Ideas que sirvieron para pensar la educación como una política cultural impulsada por el Estado y, en el caso particular de la educación rural, de reflexionar sobre cómo esta fue definida por las elites y qué tensiones o contradicciones se pueden observar en su puesta en marcha en el nivel local.

En esta lógica, Marco Calderón se acerca a la historia de la educación con una mirada entrenada en el análisis sociológico y antropológico, y también con la frescura de quien escudriña el pasado con curiosidad contagiosa, desmontando escenarios y develando voces en contrapunto, preguntando a cada paso por qué, para luego rearmar, pieza por pieza, el rompecabezas de la historia dando forma a nuevos y acuciosos relatos.

* Doctora en Educación. Profesora-investigadora. Línea de investigación: Historia social y cultural de la educación. Departamento de Estudios en Educación, Centro Universitario de Ciencias Sociales y Humanidades, Universidad de Guadalajara. México. mggaarcia.alcaraz@gmail.com 
A lo largo de los capítulos, el autor argumenta en torno a tres ejes analíticos que sirven de guía para comprender la relación entre la educación rural, los mundos indígenas y campesinos, y las políticas de intervención del Estado: que el cambio cultural propuesto estuvo sujeto a múltiples tensiones y tomó variadas formas, mezclándose lo indígena, lo católico y las visiones democrático-republicanas; que hubo tensiones entre las tradiciones y necesidades indígenas y las intervenciones fraguadas por intelectuales y políticos, lo que llevó a conflictos permanentes en la mentalidad de las elites, mismos que quedaron sin resolver en los discursos de la época; que el cambio cultural estuvo vinculado a la investigación científica, de tal modo que esta fuese el sustento de las acciones de los agentes mediadores, cuyo centro de operación fue una escuela rural que se concibió bajo la sombra de la escuela urbana.

El libro inicia planteando cómo se configuró el discurso del Estado en torno a la educación rural y el indigenismo. En los capítulos siguientes se dilucida la imbricación entre educación y experimentos sociales, centrando la mirada tanto en la escuela rural como en las misiones culturales (MC). En sus inicios, las MC tuvieron como propósito central capacitar a los maestros de una región en cuestiones pedagógicas y prácticas, para que ellos, al regresar a sus comunidades, operaran el cambio. Sin embargo, los efectos rápidamente se diluían, por lo que las misiones culturales se replantearon. En una segunda etapa las misiones se consolidaron como centros de experimentación, es entonces que se hacen "permanentes" y trabajan por periodos más largos en Xocoyucan, Actopan y Carapan.

La antropología y la arqueología proveyeron los conocimientos necesarios para la definición de estos "campos de experimentación". La educación, como política cultural, tuvo como núcleo de operación la escuela, pero ni se redujo a ese espacio, ni se limitó al desarrollo de contenidos escolares, pues se desplegaron actividades intelectuales, de salud física, higiene, educación estética y de promoción económica. En la formulación y operación de estas propuestas participaron tanto miembros de la elite intelectual como agentes mediadores. Entre los primeros destacan personajes como Manuel Gamio, Carlos Basauri y Moisés Sáenz, y en el segundo grupo se encuentran los profesores, trabajadoras sociales, médicos, enfermeras y agrónomos, quienes participaban en el estudio previo, el diseño del programas de intervención y en el trabajo directo con la población.

El autor del libro subraya el trabajo de dos agentes del Estado que se mueven en el ámbito local; por un lado, los docentes de las comunidades rurales, la mayoría de ellos en condición de aislamiento y sin las herramientas intelectuales y materiales para llevar a cabo las tareas educativas, sociales y culturales que les exigía el Estado. Por otro lado, las trabajadores sociales, quienes provistas de un utillaje mental urbano - que incluía concepciones en torno a los roles de la mujer, al funcionamiento de la familia e ideas descalificadoras acerca de los indígenas-, buscaban mejorar las condiciones de vida de la población en aspectos relacionados con la higiene, alimentación, generación de productos para su venta y actividades para un "sano esparcimiento". 
El doctor Calderón postula que la modernidad posrevolucionaria y los intelectuales de Estado no lograron desprenderse de las visiones sobre lo indígena y lo rural, que hunden sus raíces en los últimos años del siglo XIX, para lo cual muestra con detalle cómo, desde la Sociedad Indianista Mexicana y en el Congreso Indianista, se asumía que los habitantes del campo eran seres sumidos en el atraso, en la pobreza, en la ignorancia. Incluso, en algunos casos se llegó a plantear una especie de involución, argumentando que la grandeza de las razas precolombinas se degradó por el sometimiento durante la época colonial. Surgieron entonces dudas sobre la posibilidad de resarcir ese letargo, para lo cual se hicieron estudios que corroboraron la "existencia de inteligencia" en las mentes indígenas, lo que abría la posibilidad de redimirlos, hacerlos partícipes del progreso, hacerlos productivos, incorporarlos a la nación. Sobre estas ideas se elaboran varios proyectos para intervenir en el campo, y la educación rural se definió poco a poco como una instancia civilizatoria, en oposición a la barbarie en la que vivían los indígenas, en un arco temporal que va de la creación de la SEP, con Vasconcelos, hasta los albores del cardenismo.

En este punto vale la pena detenerse un poco para preguntar: ¿Qué modelo de sociedad pretendía crear el Estado a través de maestros y misioneros? ¿Qué relaciones, comportamientos, ideas y creencias se buscaba reconfigurar en un mundo rural opuesto a la modernidad que pretendía imponerse? A través de la lectura de este libro es posible acercarse a las siguientes respuestas. La racionalidad instrumental del Estado posrevolucionario suponía la reconfiguración de un individuo social homogenizado por un idioma común y por ciertos patrones de conducta y formas de pensamiento uniformes, en oposición a las tradiciones comunales de muchas poblaciones rurales. El Estado y sus agentes, asumen lo indígena/rural como entidades sumidas en el atraso, pero paradójicamente, también como poseedoras de potencial de cambio, lo cual solo sería posible a través de la intervención. El Estado, para lograr el avance de la modernidad, se despliega en distintos ámbitos — político, económico y cultural—, los cuales están presentes en los experimentos sociales estudiados, y en ellos se imbrica la creación de nuevas conciencias. En palabras de Norbert Elias (1994), las configuraciones y reconfiguraciones sociales, o sus intentos, se despliegan en el plano no solo de las estructuras materiales, sino también de las simbólicas, proceso no exento de tensiones.

Estas formas de intervención de la SEP, a través de los programas educativos y sociales que se ponen en operación, son objeto de un minucioso análisis en el libro que aquí se reseña, lo que permite conocer y comprender cómo y por qué la escuela se convierte en un espacio de construcción de nuevas identidades socioculturales, de otras forma de pensar, y en un lugar para trasformar las dinámicas familiares y comunitarias. Para esos años, como bien lo resuelve el autor, la educación no es solo cubrir los contendidos académicos establecidos en los planes y programas de estudio. No, la educación es vista como un espacio para la trasformación social, lo cual implicaba que los maestros y misioneros culturales implementaran proyectos y programas 
para incentivar la producción económica de las localidades, modificar la prácticas cotidianas ligadas a la higiene, la salud, la alimentación, la disposición y organización de la casa y de la familia, la mejora de los caminos vecinales, las formas de producción y de comercialización de los productos agrícolas, ganaderos y forestales. Por ello las misiones culturales eran equipos multidisciplinares.

Sin embargo, los cambios culturales no fueron un asunto sencillo de lograr, pues las trabajadoras sociales, los médicos y maestros, es decir, ese conjunto de promotores, esos agentes del Estado, pasaron también por conflictos y desalientos. La oposición de la población, los avances y retrocesos, los conflictos al interior de las comunidades, la insuficiencia de los recursos, las extensas jornadas de trabajo y la incomprensión de los pobladores fueron constantes. A final de cuentas, los campesinos e indígenas no fueron cuencos vacíos en los que se depositó el mensaje del Estado, sino que tuvieron cierto potencial para rechazar, simular o adoptar aquello con lo que lograron conectarse. En este sentido, los procesos de modernización ensayados en el periodo no estuvieron exentos de contradicciones, tales como la concentración del poder y la toma de decisiones frente a procesos que suponían o requería cierta democratización por vía de la participación social; la idealización de los programas frente a las dificultades de su operación práctica y, finalmente, la imposición de proyectos frente a la sublimación o negación de los conflictos. Por eso, por ejemplo, Elena Landázuri, personaje destacado dentro de las MC, llegó a reconocer que civilizar era una tarea compleja y que las mentes de los campesinos son diferentes a las mentes de la gente de la ciudad. En este mismo sentido, en Xocoyucan, Tlaxcala, en Actopan o en el Valle del Mezquital en Hidalgo, Carlos Basauri y Catalina Vesta, al trabajar con población Otomí, llegan a considerar a los indígenas apáticos, flojos y miserables, por lo que urgían a intervenir en las familias y crear nuevos espacios de sociabilidad (Calderón, 2015: 278-279, 281-282).

El público lector encontrará en este libro una ventana para mirar con nitidez la configuración de un problema que hoy está en la palestra del debate educativo: la homogenización de las identidades sociales a través de la educación, de cara a la inclusión y a la diversidad cultural. Problema que puede expresarse también en los siguientes cuestionamientos presentes desde la época en la que se ubica el texto del doctor Calderón: ¿Es posible una síntesis entre lo rural y lo urbano, entre las culturas indígenas y la civilización occidental, o son formas de vida en permanente antítesis? ¿La tensión se resuelve solo con aceptar la diversidad? ¿Cuál es el papel de la escuela como promotora del cambio? ¿Qué cambio, por qué, para qué y para quién o para quiénes?

\section{Referencia}

Elias, N. (1994). El proceso de la civilización. Investigaciones sociogenéticas y psicogenéticas. México: Fondo de Cultura Económica.

Diálo@os sobre Educación año 11 | número 21 | julio-diciembre 2020 | ISSN 2007-2171 